\title{
Comment on "Effect of Riociguat and Sildenafil on Right Heart Remodeling and Function in Pressure Overload Induced Model of Pulmonary Arterial Banding"
}

\author{
Asger Andersen \\ Aarhus University Hospital, Dep. Cardiology, Denmark \\ Correspondence should be addressed to Asger Andersen; asgerandersen@gmail.com
}

Received 28 January 2018; Accepted 1 August 2018; Published 19 August 2018

Academic Editor: Claudio De Lucia

Copyright (c) 2018 Asger Andersen. This is an open access article distributed under the Creative Commons Attribution License, which permits unrestricted use, distribution, and reproduction in any medium, provided the original work is properly cited.

It was a pleasure to read the paper "Effect of Riociguat and Sildenafil on Right Heart Remodeling and Function in Pressure Overload Induced Model of Pulmonary Arterial Banding" by Rai and colleagues [1] in the recent issue of BioMed Research International. It is an important topic and by using magnetic resonance imaging (MRI) to characterize right ventricular $(\mathrm{RV})$ performance it adds to previous studies on the same subject [2-6]. The authors conclude that both sildenafil and riociguat prevent RV failure in mice subjected to pulmonary artery banding (PAB) based on improvement in stroke volume (SV) and ejection fraction (EF). It does however seem that there is a miscalculation in the EF and SV parameters reported by the authors. By using the parameters reported by the authors to recalculate, SV is reduced and the improvement in $\mathrm{EF}$ is less pronounced in riociguat treated animals which would change the interpretation of the results. Stroke volume was calculated based on MRI derived parameters as $\mathrm{SV}=\mathrm{EDV}-\mathrm{ESV}$ and $\mathrm{EF}$ was calculated as $\mathrm{EF}=\mathrm{SV} / \mathrm{EDV}$. EDV is reported as $79.6 \mu \mathrm{l}$ (placebo), $59.9 \mu \mathrm{l}$ (sildenafil), and $44.0 \mu \mathrm{l}$ (riociguat). ESV is reported as $54.7 \mu \mathrm{l}$ (placebo), $33.9 \mu \mathrm{l}$ (sildenafil), and $24.7 \mu \mathrm{l}$ (riociguat). This would yield an EF of $31 \%$ (placebo), $43 \%$ (sildenafil), and $44 \%$ (riociguat) and a SV of $24.9 \mu \mathrm{l}$ (placebo), $26 \mu \mathrm{l}$ (sildenafil), and $19.3 \mu \mathrm{l}$ (riociguat). The authors report EF of $30 \%$ (placebo), $45 \%$ (sildenafil), and 58\% (riociguat) and a SV of 24.2 (placebo), 25.9 (sildenafil), and $28.5 \mu \mathrm{l}$ (riociguat). This discrepancy should be clarified, as it could potentially change the interpretation and the conclusion of the present study.
Another comment is that previous studies with a similar design in a rat PAB model [6] found that mortality was increased with the soluble guanylate cyclase (sGC) stimulator BAY 41-2272 (a compound similar to riociguat). It should be reported in the paper by Rai and colleagues whether there was any mortality in the treatment arms in this study, as this could potentially introduce a selection bias.

I hope that the authors will address the comments above to improve the knowledge on sGC-cGMP stimulation in RV failure.

\section{Conflicts of Interest}

The author declares that they have no conflicts of interest.

\section{References}

[1] N. Rai, S. Veeroju, Y. Schymura et al., "Effect of Riociguat and Sildenafil on Right Heart Remodeling and Function in Pressure Overload Induced Model of Pulmonary Arterial Banding," BioMed Research International, vol. 2018, Article ID 3293584, 9 pages, 2018.

[2] A. Andersen, J. M. Nielsen, C. D. Peters, U. K. Schou, E. Sloth, and J. E. Nielsen-Kudsk, "Effects of phosphodiesterase-5 inhibition by sildenafil in the pressure overloaded right heart," European Journal of Heart Failure, vol. 10, no. 12, pp. 1158-1165, 2008. 
[3] S. Schäfer, P. Ellinghaus, W. Janssen et al., "Chronic inhibition of phosphodiesterase 5 does not prevent pressure-overload-induced right-ventricular remodelling," Cardiovascular Research, vol. 82, no. 1, pp. 30-39, 2009.

[4] M. A. J. Borgdorff, B. Bartelds, M. G. Dickinson et al., "Sildenafil enhances systolic adaptation, but does not prevent diastolic dysfunction, in the pressure-loaded right ventricle," European Journal of Heart Failure, vol. 14, no. 9, pp. 1067-1074, 2012.

[5] M. A. Borgdorff, B. Bartelds, M. G. Dickinson et al., "Sildenafil treatment in established right ventricular dysfunction improves diastolic function and attenuates interstitial fibrosis independent from afterload," American Journal of Physiology-Heart and Circulatory Physiology, vol. 307, no. 3, pp. H361-H369, 2014.

[6] A. Andersen, J. M. Nielsen, S. Holmboe, M. D. Vildbrad, and J. E. Nielsen-Kudsk, "The effects of cyclic guanylate cyclase stimulation on right ventricular hypertrophy and failure alone and in combination with phosphodiesterase-5 inhibition," Journal of Cardiovascular Pharmacology, vol. 62, no. 2, pp. 167-173, 2013. 


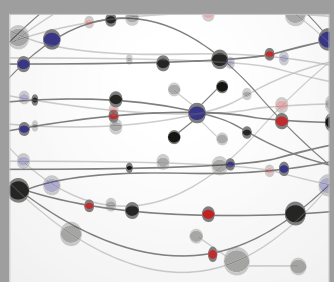

The Scientific World Journal
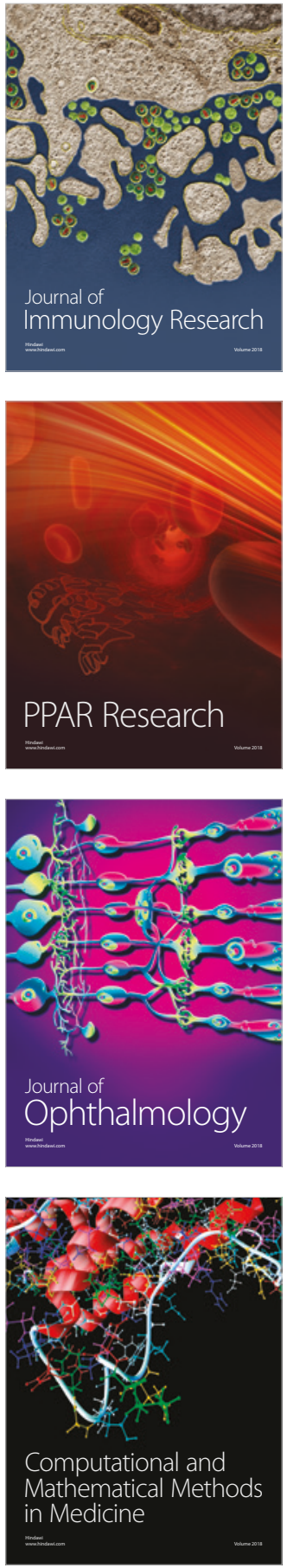

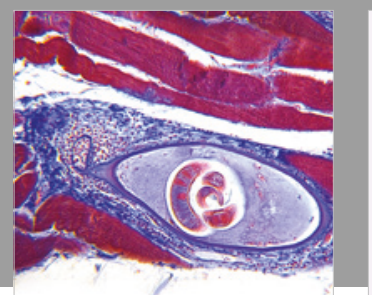

Gastroenterology Research and Practice

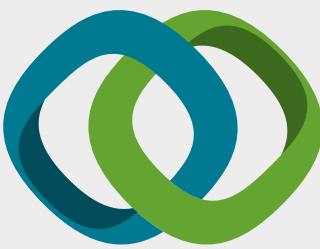

\section{Hindawi}

Submit your manuscripts at

www.hindawi.com
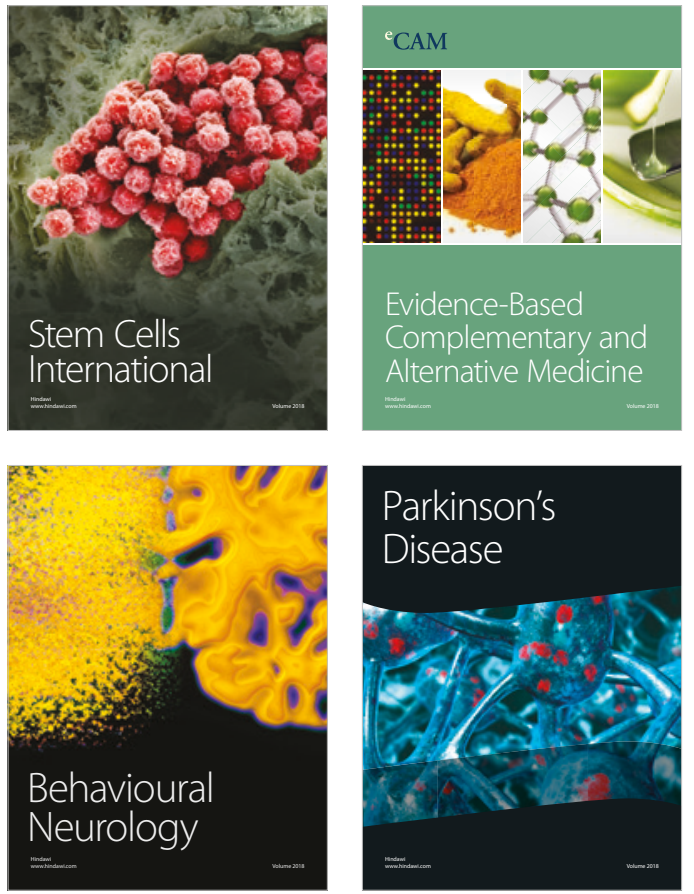

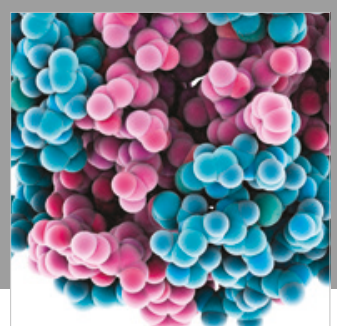

ournal of

Diabetes Research

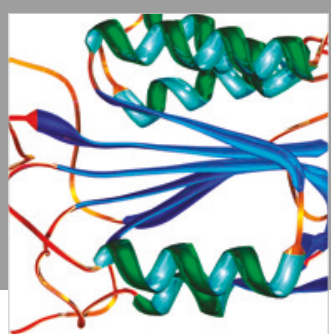

Disease Markers
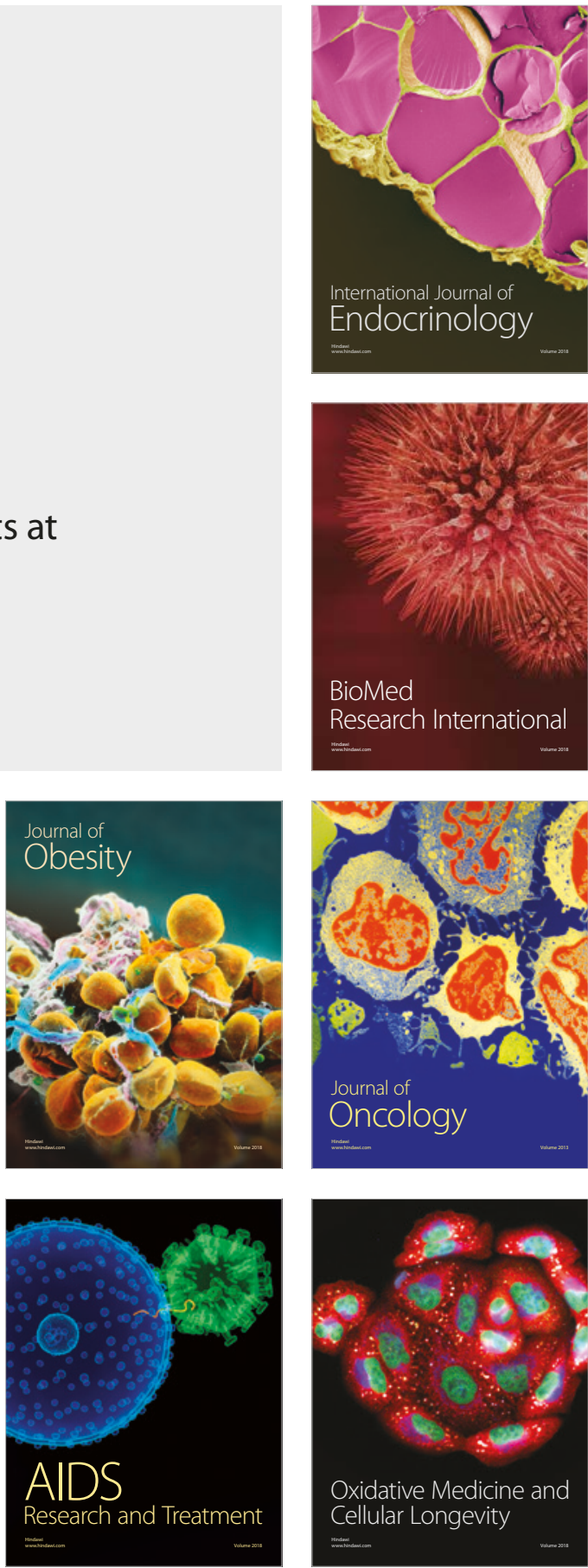